\title{
ACTIVATION-ANALYSIS OF TRACE COBALT IN TISSUE USING 10.5-MINUTE 60m-COBALT
}

\author{
David G. KaIser* and W. Wayne MeInKe \\ Department of Chemistry, University of Michigan, Ann Arbor, Michigan, U.S.A.
}

(Received 7 August 1959)

Summary-Microgram amounts of cobalt from vitamin $\mathbf{B}_{12}$ have been analyzed by rapid activationanalysis in rat kidney tissue as well as in vitamin preparations. A 15 -minute radiochemical separation procedure coupled with gamma-ray spectrometry permitted utilization of the 10.5 -min ${ }^{80} \mathrm{~m}$ Co radioisotope. With this procedure the lower limit of detection at a thermal neutron flux of $10^{12} \mathrm{n} / \mathrm{cm}^{2} \mathrm{sec}$ was about $5 \times 10^{-8}$ grams of cobalt.

\section{INTRODUCTION}

SINCE the advent of vitamin $\mathrm{B}_{12}$ as a medicinal for the treatment of certain hæmatological disorders, considerable attention has been focused on the determination of cobalt in biological systems. Saltzman and Keenan ${ }^{1}$ have presented a review of the methods used for the microdetermination of cobalt in biological materials. Determination of this element by conventional wet chemical procedures coupled with spectroscopy or sensitive colour reactions frequently lacks sensitivity or is complicated by trace contamination from the reagents. In many cases, however, the use of radioisotopes can offer a rapid and sensitive procedure to assist in this analysis.

Until now much effort has gone into using radioactive tracers of cobalt, or labelled vitamin $B_{12}$, in exploring the distribution of this element in biological systems. Several procedures have been described for the production of vitamin $\mathrm{B}_{12}$ labelled with ${ }^{60} \mathrm{Co}$ either by a biosynthetic route ${ }^{2,3}$ or by direct slow neutron irradiation. ${ }^{4}$ This labelled vitamin is available routinely ${ }^{5}$ for tracer studies of pernicious anæmia in humans and is used in an isotope-dilution method for the assay of vitamin $B_{12}$ as described in the U.S. Pharmacopoeia. ${ }^{6}$

Published studies of tracer distributions include work with injected ${ }^{60} \mathrm{Co}$ in polycythemic rats, ${ }^{7}$ metabolism of ${ }^{60} \mathrm{Co}$-labelled vitamin $\mathrm{B}_{12}$ by the rat, ${ }^{8}$ and the distribution of orally administered ${ }^{56} \mathrm{Co}$-labelled vitamin $\mathrm{B}_{12} \cdot{ }^{9}$

Another method for determining the distribution of trace amounts of cobalt in a system is to analyse directly for this element but for many systems the sensitivities required eliminate most standard analytical techniques. Activation-analyses for trace amounts of cobalt have, however, been made on many types of samples using the long-lived ${ }^{60} \mathrm{Co}$. Smales, Mapper and Wood ${ }^{10}$ have given an excellent discussion of the procedures used in the analysis of rocks and marine sediments by this technique. They checked the accuracy of their methods by analysing standard steel samples and report working sensitivities for cobalt of about $10^{-8}$ grams. The disadvantage of this method is that the 5.2-year ${ }^{60} \mathrm{Co}$ formed requires a long activation to attain these sensitivities and many days may elapse between the time that an analysis is started (the beginning of the irradiation) and the time that the results can be obtained.

\footnotetext{
* Present address: The Upjohn Company, Kalamazoo, Michigan.
} 
We have been using the facilities of the Ford Nuclear Reactor at the University of Michigan to explore the use of short-lived radio-isotopes in activation-analysis. These rapid activation and measurement facilities have been coupled with a fast radiochemical separation to determine cobalt (by the $10.5-\mathrm{min}{ }^{60 \mathrm{~m}} \mathrm{Co}$ ) in the kidneys of rats that had been given unlabelled vitamin $\mathbf{B}_{12}$.

\section{EXPERIMENTAL}

\section{Apparatus}

Samples were irradiated in polyethylene snap-type "rabbits" in the pneumatic tube system of the Ford Nuclear Reactor of the University of Michigan. This system permits irradiations at thermal neutron fluxes of about $10^{12} \mathrm{n} / \mathrm{cm}^{2} \mathrm{sec}$ (when the reactor is operating at full power of 1 megawatt) and delivery to a hood in the neighbouring Michigan Memorial Phoenix Laboratory within 3 seconds after the end of irradiation. Samples were then worked up chemically and were measured by a $3^{\prime \prime} \times 3^{\prime \prime} \mathrm{NaI}(\mathrm{Tl})$ crystal coupled with a special 100-channel pulse-height analyzer with duplicate memories. This equipment has been described in detail elsewhere. ${ }^{11-13}$

\section{Preparation of animals and tissue}

Holtzman* albino male rats weighing between 275 and $350 \mathrm{~g}$ were used in this study. They were maintained on Rockland Rat Diet $\uparrow$ and had free access to drinking water. With the exception of animals No. 1 and 2, intraperitoneal injections of vitamin $B_{12}+$ containing 45 micrograms $\$$ of were administered 10 to 12 hours before sacrificing. Animal No. 1 received three 45 microgram doses 24 hours apart while animal No. 2 received two doses 24 hours apart. Both the kidneys and the liver tissue were surgically removed for analysis; however, the kidneys were found to be more readily adaptable to the chemical procedure.

The weighed tissues were allowed to air dry at room temperature for 24 hours and then re-weighed. They were placed in envelopes prepared from 4 mil thick polyethylene film, which were closed by heat sealing. The sealed sample was then irradiated in the "rabbit" along with suitable monitoring foils for a period of 30 minutes at full power.

\section{Radiochemical separation}

While the sample was being irradiated a nickel crucible was prepared containing $10 \mathrm{mg}$ of Co carrier solution plus a known amount of 5.2 -year ${ }^{80} \mathrm{Co}$ tracer. Three sodium hydroxide pellets were added and the solution heated almost to dryness. Two minutes before the end of the irradiation $10 \mathrm{~g}$ of sodium peroxide were added to the crucible and melted.

The irradiated sample was then fused in this melt for 1 minute. (CAUTION: A cover must be used on the crucible since the reaction may be quite violent.) The outside of the crucible was then cooled by dipping it into a beaker of cold water and the melt made to solidify in a thin, readily dissolved coating by manipulation of the crucible. The melt was then dissolved by immersion in $50 \mathrm{ml}$ of distilled water, and $50-70 \mathrm{ml}$ of liquid nitrogen were added to cool the solution to room temperature. Fifteen to twenty $\mathrm{ml}$ of glacial acetic acid were then added slowly and the solution was again cooled with liquid nitrogen.

This mixture at a $\mathrm{pH}$ of 5-6 was then transferred to a 150-ml separatory funnel containing $25 \mathrm{ml}$ of 8-hydroxyquinoline solution ( $3 \%$ solution in chloroform) and shaken for 1 minute. Ten $\mathrm{ml}$ of $9 M \mathrm{HCl}$ were used to re-extract the cobalt from the organic layer. Co was then precipitated as the oxide from the $\mathrm{HCl}$ solution by addition of $\mathrm{Na}_{2} \mathrm{O}_{2}$. This precipitate was collected on a filter chimney, I was washed with water, and mounted for measurement on the spectrometer. The entire procedure could be completed in about 15 minutes with an average recovery of about $40 \%$ of the cobalt.

* Holtzman Company, Madiscn 4, Wisconsin.

$\dagger$ A product of Rockland Farms, New City, N.Y.; Manufactured by A. E. Staley Mfg. Co., Chicago 27, Illinois.

F Injection Vitamin $\mathbf{B}_{12},(1000$ micrograms/ml.), University Hospital Control No. 1104580, Ann Arbor, Michigan.

$\S$ Based on the value of $4.5 \%$ as the amount of Co in Vitamin $\mathrm{B}_{12}$ N. G. Brink, et al., J. Amer. Chem. Soc., $1949,71,1854$.

II If foaming occurs add $10-15 \mathrm{ml}$ of $0.1 \mathrm{M} \mathrm{HCl}$. 
Activity determination

Linearity of the measurement system was established by the use of ${ }^{137} \mathrm{Cs},{ }^{60} \mathrm{Co},{ }^{203} \mathrm{Hg},{ }^{75} \mathrm{Se}$, and ${ }^{113}$ Sn standards. Spectra were obtained in the energy ranges of about $0-0.25$ and $0-2.0 \mathrm{MeV}$ as shown in Fig. 1. The amount of ${ }^{60 \mathrm{~m}} \mathrm{Co}$ was determined from the area under the $0.059 \mathrm{MeV}$ photopeak while correction for chemical yield was made by measuring the recovery of the long lived tracer ${ }^{80} \mathrm{Co}$ utilizing the 1.17 and $1.33 \mathrm{MeV}$ photopeaks.

\section{Monitoring procedures}

Gold foils weighing between 0.5 and $1.0 \mathrm{mg}$ were wrapped in plastic envelopes and scotch taped to the inside of the cap of the "rabbit." Following irradiation the foils were dissolved in $4 \mathrm{ml}$ of aqua regia and diluted to $10 \mathrm{ml}$ with distilled water. An aliquot of this solution was placed on a filter paper and mounted for measurement of the $411 \mathrm{keV}$ gamma ray of ${ }^{198} \mathrm{Au}$ on the spectrometer. Comparison with other measurements made with calibrated gold foils permitted normalization of all irradiations to a neutron flux of $1 \times 10^{12}$.

\section{RESULTS AND DISCUSSION}

Preliminary experiments were carried out using this procedure without the chemical scparation on pure matcrials. Aliquots of the Vitamin $\mathbf{B}_{\mathbf{1 2}}$ injection werc sealed in polyethylene tubing and irradiated in the same manner as described for the kidney samples. Spectral determinations in the $0-0.25 \mathrm{MeV}$ range permitted the measurement of peak areas for the $0.059 \mathrm{MeV}$ gamma ray emitted during the decay of the ${ }^{60 \mathrm{~m}} \mathrm{Co}$. Successive spectra, taken at several-minute intervals, showed that the peak decayed with the 10.5-minute half life of this isomer. Analysis of decreasing concentrations of Vitamin $B_{12}$ showed the lower practical limit of detection to be about $5 \times 10^{-8} \mathrm{~g}$ of cobalt. The same procedure was performed on cobalt nitrate solutions with similar results.

Preliminary studies to determine the level of naturally occurring Co in normal rat kidney tissues indicated that it was less than $10^{-8} \mathrm{~g}$, or below the limits of detection for this method at a flux of $10^{12}$. Thus experiments were conducted to determine the tissue level of $\mathrm{Co}$ after administration to the rat of a Co-containing pharmaceutical (Vitamin $B_{12}$ ).

Determinations made on tissues from ten different rats show that this method is readily applicable to $\mu \mathrm{g}$ amounts of $\mathrm{Co}$ in biological systems. The results, summarized in Table I, indicate that under the conditions of these experiments 1-3 $\mu \mathrm{g}$ of Co are found in rat kidney tissue 10-12 hours after the intraperitoneal administration of $45 \mu \mathrm{g}$ of $\mathrm{Co}$ as Vitamin $\mathrm{B}_{12}$. This does not indicate that the Co is present as Vitamin $B_{12}$ in the kidney but rather that the Co portion of the molecule is excreted via the kidney.

The chemical procedure went sm oothly although $\mathrm{Cu}$ and $\mathrm{Mn}$ were found to be interfering elements. These elements are present in considerably greater quantities than $\mathrm{Co}$ in the kidney and this particular rapid procedure did not separate them completely. Half-life studies and energy determinations with the gamma spectrometer indicated that the 12.8 -hour ${ }^{64} \mathrm{Cu}$ and 2.6 -hour ${ }^{56} \mathrm{Mn}$ were responsible for the contamination. Attempts to reduce this contamination by extractions with EDTA, dithizone, and $\mathrm{NH}_{4} \mathrm{CNS}$ resulted in a significant decrease in the per cent recovery of the Co. Since for our work we were able to separate and determine the Co radiations by gamma spectrometry in the presence of the $\mathrm{Cu}$ and $\mathrm{Mn}$, no further refinement of the chemical procedure was attempted at this time.

It should be pointed out that somewhat higher sensitivities can be obtained in 
David G. Kaiser and W. Wayne Meinke

TABLE 1.-ACTIVATION ANALYSIS FOR COBALT IN RAT KIDNEY TISSUE USING ${ }^{60 \mathrm{~m} C O}$

\begin{tabular}{c|c|c|c|c|c}
\hline $\begin{array}{c}\text { Animal } \\
\text { number }\end{array}$ & $\begin{array}{c}\text { Live } \\
\text { weight } \\
\text { (gms.) }\end{array}$ & $\begin{array}{c}\text { Co administered } \\
\text { as vitamin } \mathbf{B}_{12} \\
(\mu \mathrm{g})\end{array}$ & $\begin{array}{c}\text { Fresh } \\
\text { kidney } \\
\text { weight } \\
(\text { gms.) }\end{array}$ & $\begin{array}{c}\text { Yield of separation } \\
\text { procedure }(\%)\end{array}$ & $\begin{array}{c}\text { Co found in } \\
\text { kidneys } \\
(\mu \mathrm{g})^{*}\end{array}$ \\
\hline 1 & 335.7 & 135 & 2.47 & 39.4 & \\
2 & 323.4 & 90 & 2.02 & 40.3 & 6.85 \\
3 & 315.3 & 45 & 2.38 & 23.8 & 3.60 \\
4 & 268.1 & 45 & 1.87 & 38.8 & 1.80 \\
5 & 287.2 & 45 & 2.12 & 49.5 & 3.37 \\
6 & 363.0 & 45 & 2.19 & 50.4 & 2.18 \\
7 & 374.0 & 45 & 2.28 & 44.3 & 1.60 \\
8 & 349.3 & 45 & 2.27 & 53.8 & 2.56 \\
9 & 259.2 & 45 & 1.98 & 35.7 & 1.25 \\
10 & 363.5 & 45 & 2.10 & 36.9 & 1.94 \\
\hline
\end{tabular}

* Corrected to neutron flux of $1 \times 10^{12} \mathrm{n} / \mathrm{cm}^{2} \mathrm{sec}$.

activation-analysis when gross gamma counting is used instead of spectrometry. Thus an improvement in the specificity of the Co separation to reduce the $\mathrm{Cu}$ and $\mathrm{Mn}$ to a point where the ${ }^{60 \mathrm{~m}} \mathrm{Co}$ activity is the primary activity present would permit
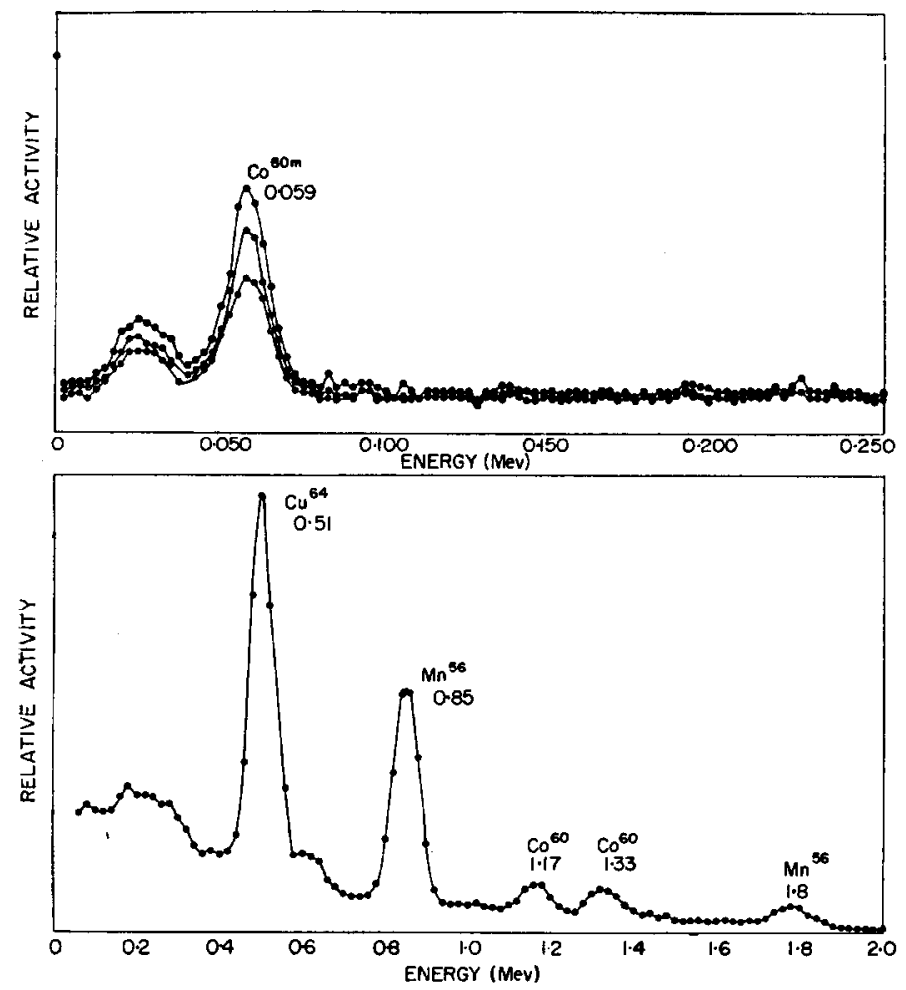

Fig. 1.-Gamma-ray spectra of cobalt fraction separated from rat kidney tissue. Spectra in top curve taken at four-minute intervals. Bottom curve taken after short-lived ${ }^{60 \mathrm{~m}} \mathrm{Co}$ has decayed out. 
utilization of this method without elaborate spectrometry equipment and in addition would probably increase the sensitivity by a factor of 2-5.

The variability of individual rats does not permit an exact evaluation of this method such as is possible using standard samples of alloys, etc. The results of Table I do, however, show the right order of magnitude for the relative values. The overall reproducibility of the method for tissue samples was shown to be around $10 \%$ at these microgram levels by several runs in which known amounts of cobalt were added to rat liver before the analysis.

Preliminary investigations have also shown that this procedure may be readily adapted to the analysis of Co-containing vitamin capsules such as Myadec.* Single gelatin capsules were irradiated and subjected to the previously described chemical separation. Since $\mathrm{Cu}$ and $\mathrm{Mn}$ were also separated with this procedure a simultaneous determination of these elements could be performed using gamma spectrometry. The spectra obtained for this type of sample are quite similar to those shown in Fig. 1.

\section{CONCLUSION}

Thermal neutron activation analysis has definite advantages over tracer studies for the determination of pharmaceutical localization. For medicinals amenable to this type of procedure the advantages are (1) the biological system is not exposed to radiation during the course of the experiment, (2) utilization of short-lived radioisotopes reduces the possibility of prolonged contamination, and (3) there is no problem of disposal of contaminated animal wastes such as carcasses or excreta. In addition, analysis by activation eliminates the problem of reagent blanks, so common to other analytical techniques.

Furthermore, the use of 10.5 -min ${ }^{60 m} \mathrm{Co}$ in activation-analysis has been shown to be feasible and permits completion of analyses of this sort within a period of an hour or so rather than of days or weeks.

Acknowledgements-This work was supported by the Michigan Memorial Phoenix Project and the U.S. Atomic Energy Commission. Thanks are due to Professor H. J. Gomberg, C. W. Ricker and the staff of the Ford Nuclear Reactor for their help in making the irradiations.

Zusammenfassung-Microgrammengen von Cobalt aus Vitamin $\mathbf{B}_{12}$ wurden im Gewebe von Rattennieren und auch in Vitaminpräparaten bestimmt. Es wurde eine Schnellaktivierungsmethode verwendet. Eine 15-Minuten radiochemische Trennungsmethode in Verbindung mit Gammstrahlenspectrometrie gestattete die Verwendung des $10.5 \mathrm{Min} .{ }^{60 \mathrm{~m}} \mathrm{Co}-I$ sotopes. Bei der Methode lag die untere Grenze der Bestimmbarkeit bei einem von einem Thermal-Neutronen Strom von $10^{12} \mathrm{n} / \mathrm{cm}^{2} \mathrm{sec}$ bei etwa $5 \times 10^{-8}$ gram Cobalt.

Résumé-On dose quelques microgrammes de cobalt provenant de vitamine $B_{12}$, issue de tissus de rein de rat aussi bien que de préparations de vitamine, par une analyse par activation rapide. Une méthode de séparation radio-chimique de 15 minutes associée à une spectrometrie gamma permet l'utilisation de radioisotope $10,5 \mathrm{~min}{ }^{80 \mathrm{~m}} \mathrm{Co}$. Par ce procédé la limite inférieure de détection pour un flux de neutrons thermiques de $10^{12} \mathrm{n} / \mathrm{cm}^{2} \mathrm{sec}$. est d'environ $5 \times 10^{-8}$ gramme de cobalt.

\section{REFERENCES}

${ }^{1}$ B. E. Saltzman and R. G. Keenan, Microdetermination of Cobalt in Biological Materials in Methods of Biochemical Analysis, by D. Glick, ed., Interscience Publishers, Inc., N.Y., 1957, Vol. 5, 181.

${ }^{2}$ L. Chaiet, C. Rosenblum, and D. T. Woodbury, Science, 1950, 111, 601.

* Myadec-Therapeutic Vitamin Capsule: Parke, Davis and Co., Detroit, Michigan. 
${ }^{3}$ C. Rosenblum and D. T. Woodbury, ibid., 1951, 113, 215.

4 R. C. Anderson and Y. Delabarre, U.S. Atomic Energy Commission Report AECU-1402; Nuclear Sci. Abstr., 1951, 5, 5007.

s Abbott Radio-Pharmaceuticals Price List; Abbott Laboratories, North Chicago, Illinois: 1958, 5 .

- Pharmacopoeia of United States of America, U.S.P. XV., Supplement 1, U.S. Pharmacopoeia Convention, Inc., 46 Park Ave., New York, 1956, 21.

' N. I. Berlin, J. Biol. Chem., 1950, 187, 41.

${ }^{8}$ K. W. Barbee and B. C. Johnson, Proc. Soc. Exptl. Biol. Med., 1951, 76, 720.

${ }^{9}$ C. C. Booth and D. I. Mollin, Brit. I. Haematol, 1956, 2, 223.

${ }^{10}$ A. A. Smales, D. Mapper and A. J. Wood, Analyst, 1957, 82, 75.

${ }^{11}$ W. W. Meinke, Nucleonics, 1959, 17, No. 9, 86.

${ }^{12}$ W. W. Meinke, U.S. Atomic Energy Commission Report AECU-3641, November 1957.

${ }^{13}$ W. W. Meinke, U.S. Atomic Energy Commission Report AECU-3887, November 1958. 